\title{
TRPM2 promotes the proliferation and invasion of pancreatic ductal adenocarcinoma
}

\author{
RUI LIN*, YUFENG WANG*, QUANNING CHEN, ZHONGYAN LIU, \\ SHUAI XIAO, BINGYI WANG and BAOMIN SHI
}

Department of General Surgery, Tongji Hospital, Tongji University School of Medicine, Shanghai 200065, P.R. China

Received July 7, 2017; Accepted January 29, 2018

DOI: $10.3892 / \mathrm{mmr} .2018 .8816$

\begin{abstract}
The aim of the present study was to investigate transient receptor potential cation channel subfamily M member 2 (TRPM2), a promising therapeutic target and biomarker for pancreatic ductal adenocarcinoma (PDAC) prognosis, in addition to determining its effects regarding tumor progression and invasion. PDAC is a fatal disease with a poor prognosis, and its associated pathogenic molecular mechanisms remain to be determined. In the present study, combined analysis using genomic and transcriptomic data from two PDAC studies was performed to discover a survival-associated biomarker of PDAC. Survival analysis for genes mutated in $\geq 10$ patients was performed using a Kaplan-Meier curve and tested for significance using a log-rank test. Furthermore, gene-expression correlation analysis was performed to determine the genes with the strongest correlations to TRPM2. In addition, a Cell Counting Kit- 8 assay, a scratch wound-healing assay and a Transwell assay were performed in the present study to investigate the proliferative, invasive and metastatic ability of PANC-1 cells in TRPM2-overexpressing and downregulated groups. The mutated TRPM2 gene had a strong negative correlation with patient survival probability compared with the normal control group $\left(\mathrm{P}=1.06 \times 10^{-4}\right)$. Expression of TRPM2 was strongly correlated with expression of probable phospholipid-transporting ATPase IM, $\gamma$-parvin, tudor domain containing 9, Toll-like receptor 7 and Scm-like with four MBT domains protein 2 according to the criterion of a correlation coefficient $>0.5$. Furthermore, the results of the present study demonstrated that the TRPM2 overexpression
\end{abstract}

Correspondence to: Professor Baomin Shi, Department of General Surgery, Tongji Hospital, Tongji University School of Medicine, 389 Xincun Road, Shanghai 200065, P.R. China

E-mail: baominsph@163.com

"Contributed equally

Key words: transient receptor potential cation channel subfamily $\mathrm{M}$ member 2, pancreatic ductal adenocarcinoma, Kaplan-Meier curve, log-rank test, Cell Counting Kit-8, scratch wound-healing assay, Transwell assay in a PDAC cell line (PANC-1) promoted cell proliferation, invasion and metastatic ability. TRPM2 represents a potential therapeutic target and prognostic marker for patients with PDAC. TRPM2 regulates cell proliferation, invasion and migration; however, the underlying mechanism requires further investigation in future studies.

\section{Introduction}

Pancreatic ductal adenocarcinoma (PDAC) is a disease with a poor prognosis. With increasing incidence and mortality, PDAC is the 6th most common cause of cancer-associated death in China (1). Despite advances in surgical and oncological treatment strategies, PDAC exhibits an extremely poor prognosis, with a 6 -month median survival period and $\leq 1-2 \%$ 5 -year survival rate $(2,3)$.

The exact molecular mechanism of PDAC remains undetermined. Pancreatic intraepithelial neoplasia (PanIN) in the pancreatic duct has been proposed to be the primordial precursor of PDAC (4). As PanIN progresses to carcinoma, accumulated mutations may result in the loss of cyclin-dependent kinase inhibitor 2A/p16 and/or the inactivation of cellular tumor antigen 53 and mothers against decapentaplegic homolog 4, in addition to the activation of the KRAS proto-oncogene (5). Unlike other adenocarcinomas, the usual composition of pancreatic cancer tumor is a large mass of fibroinflammatory tissue, which is interspersed with islands of neoplastic epithelia (6,7). Previous studies have suggested that pancreatic tumor stroma directly affect the progression and outcome of disease via the release of factors, including insulin-like growth factor and platelet-derived growth factor, into the tumor microenvironment that aid tumor growth and invasiveness (8-10). However, the association between differentially expressed genes and tumor cells remains poorly understood, which has limited the development of effective treatments for patients with PDAC.

The Cancer Genome Atlas (https://cancergenome.nih.gov/) may further the understanding of the molecular basis of cancer via genome analysis, including high-throughput genome sequencing. In the present study, combined analysis using genomic and transcriptomic data from two PDAC studies was performed and a survival-associated biomarker was revealed, transient receptor potential cation channel subfamily M member 2 (TRPM2). Furthermore, the role of TRPM2 in 
pancreatic adenocarcinoma cell lines was investigated using an in vitro gene silencing method. The present study provides a comprehensive investigation of TRPM2, a promising biomarker for PDAC prognosis, and investigates how TRPM2 affects tumor progression and invasion.

\section{Materials and methods}

Data analysis. Clinical information, somatic mutation and gene expression data of patients with pancreatic cancer were obtained from two previously published cancer genome studies $(11,12)$. The somatic mutation and clinical information from 483 patients with pancreatic cancer was obtained from data published by Bailey et al (11) and Waddell et al (12). The survival time of 159 patients of the total 483 patients was available, with survival status indicated as 'alive', 'deceased' or 'loss' at the final follow-up. Gene expression data of 96 patients were obtained from the Gene Expression Omnibus (13) (dataset, GSE36924) (11), while 96 patients have survival information. The samples with follow-up information were used for survival analysis.

Survival analysis of genes mutated in $\geq 10$ (out of 159) patients was performed. Patients were divided into two groups according to the mutation status of each gene. The difference in overall survival between the two groups was estimated using a Kaplan-Meier curve and tested for significance using a log-rank test. A gene was considered to be associated with patient clinical outcomes when a $\mathrm{P}<0.05$ value was obtained. Following this, patients were additionally divided into two groups, based on mutation and gene expression levels, according to the median expression values of each gene. Survival analysis was performed using gene-expression data obtained from the Gene Expression Omnibus (dataset, GSE36924) (11). It was identified that somatic mutation and gene expression of TRPM2 were significantly associated with the patient's overall survival (Tables I and II). Thus, further experimental assays were performed to investigate the role of TRPM2 in pancreatic cancer.

It was hypothesized that genes involved in a similar biological process may exhibit similar expression patterns. Gene expression correlation analysis was performed to reveal genes functionally associated with TRPM2 in patients with pancreatic cancer. Pearson's correlation coefficient between TRPM2 and each of the genes of interest was calculated. Following this, the top genes with a correlation coefficient of $>0.50$ were retained (Table III).

TRPM2 knockdown and overexpression. PANC-1 cells (American Type Culture Collection, Manassas, VA, USA) were seeded in 6-well plates until $80 \%$ confluency was reached following $24 \mathrm{~h}$ of culture at $37^{\circ} \mathrm{C}$. Hilymax-Trpm 2 siRNA complex (20 pmol/l), Hilymax-Trpm 2 OverExp vector (4 $\mu \mathrm{g} /$ well), empty vector and scramble siRNA (Generay Biotech Co., Ltd., Shanghai, China) were added to the cell culture, using the transfection agent Hilymax (Dojindo Molecular Technologies, Inc., Kumamoto, Japan) well as per the manufacturer's instructions, and incubated at $37^{\circ} \mathrm{C}$ in a $5 \% \mathrm{CO}_{2}$ incubator for $4 \mathrm{~h}$. The medium was subsequently replaced with fresh medium (RPMI 1640; $10 \%$ fetal bovine serum, Gibco; Thermo Fisher Scientific, Inc., Waltham, MA,
USA) and incubated for a further $48 \mathrm{~h}$. The untransfected group was subjected to normal culture without transfection reagent, the empty vector represented the control for TRPM2 overexpression, and scramble siRNA represented the control for TRPM2 silencing. Cells were prepared for the subsequent reverse transcription-quantitative polymerase chain reaction (RT-qPCR) and Transwell assays. The Trpm2 siRNA and Trpm2 OverExp plasmid were designed and synthesized by Generay Biotech Co., Ltd. (Shanghai, China; Table IV).

$R N A$ extraction and $R T-q P C R$. Total RNA from cells was extracted using Cell Culture and Tissue Total RNA Extraction and Preparation Mini kit (Thermo Fisher Scientific, Inc.) according to the manufacturer's instructions. The quantity and quality of RNA were confirmed using a NanoDrop 1000. The primers were designed using Primer Premier 5.0 software (Premier Biosoft International, Palo Alto, CA, USA) and synthesized by Generay Biotech Co., Ltd. (Table IV). RT-qPCR was performed using the KAPA SYBR Green Supermix PCR kit with the AriaMx Real-Time PCR System (both Agilent Technologies, Inc., Santa Clara, CA, USA). RT was performed at $50^{\circ} \mathrm{C}$ for $30 \mathrm{~min}$. qPCR conditions: Denaturing at $95^{\circ} \mathrm{C}$, $10 \mathrm{~min}$, then 40 cycles of denaturing at $95^{\circ} \mathrm{C}$ for $15 \mathrm{sec}$, annealing at $60^{\circ} \mathrm{C}$ for $1 \mathrm{~min}$, and elongation at $95^{\circ} \mathrm{C}$ for $15 \mathrm{sec}$ and $60^{\circ} \mathrm{C}$ for $15 \mathrm{sec}$. The relative expression levels among the different genes were determined using the $2^{-\Delta \Delta \mathrm{Cq}}$ method (14).

Cell proliferation assay. PANC-1 cell proliferation was investigated using the Cell Counting Kit-8 (CCK-8; Dojindo Molecular Technologies, Inc.). PANC-1 cells were seeded onto a 96-well microplate at a density of $3 \times 10^{4}$ cells/well, and the cells were transfected with either Hilymax-Trpm2 OverExp vector $(0.2 \mu \mathrm{g} /$ well $)$, Hilymax-Trpm 2 siRNA (20 pmol/l), empty vector $(0.2 \mu \mathrm{g} /$ well) and scramble siRNA (20 pmol/l). The cells were subsequently cultured for 0,24 and $48 \mathrm{~h}$. Following this, $5 \mu \mathrm{l}$ CCK-8 solution was added to each well and incubated at $37^{\circ} \mathrm{C}$ for a further $2 \mathrm{~h}$. Optical density was determined at $450 \mathrm{~nm}$ using a microplate spectrophotometer (BioTek Instruments, Inc., Winooski, VT, USA).

Scratch wound-healing assay. PANC-1 cells were seeded in 24-well plates at a density of $1 \times 10^{5}$ cells per well and incubated overnight at $37^{\circ} \mathrm{C}$. Following this, the cells were transfected with Hilymax-Trpm 2 OverExp vector $(1 \mu \mathrm{g} /$ well $)$, Hilymax-Trpm 2 siRNA (20 pmol/l), empty vector and scramble siRNA. The cells were subsequently cultured for $24 \mathrm{~h}$. The cells at the bottom of wells were then scratched using a $10 \mu \mathrm{l}$ tip and the floating cells were gently washed twice using RPMI 1640 medium. Images of each well were captured using a microscope (magnification, x100) at 0 and 24 h time intervals post-injury (Olympus X51; Olympus Corporation, Tokyo, Japan).

Transwell assay. PANC-1 cells were transfected with TRPM2 Vector, TRPM2 siRNA, empty vector and scramble siRNA. A total of $24 \mathrm{~h}$ post-transfection, the cells were seeded into Matrigel-plated upper wells with RPMI 1640 medium without serum $\left(5 \times 10^{4}\right.$ cells/well), and the lower wells contained $500 \mu \mathrm{l}$ complete medium (RPMI 1640 and 10\% fetal bovine serum), following a routine procedure. Following incubation for $48 \mathrm{~h}$ at 
Table I. Survival analysis of genes associated with the patient's overall survival.

\begin{tabular}{lll}
\hline Gene & Mutation P-value & Expression P-value \\
\hline TRPM2 & 0.0104 & 0.0111 \\
COL18A1 & 0.0384 & 0.0138 \\
THSD7B & 0.144 & 0.166 \\
FRAS1 & 0.0259 & 0.395 \\
PTPRT & 0.00367 & 0.426 \\
SCN5A & 0.102 & 0.886 \\
PXDN & 0.0301 & 0.903 \\
\hline
\end{tabular}

$37^{\circ} \mathrm{C}$, cells that did not migrate through the pores were gently removed with a cotton swab. Cells on the lower side of the insert filter were fixed by $5 \%$ glutaraldehyde for $10 \mathrm{~min}$ and stained with $1 \%$ crystal violet in $2 \%$ ethanol at room temperature for $20 \mathrm{~min}$. Numbers of cells on the underside of the filter from five randomly selected microscopic views (magnification, x100) were counted.

Statistical analysis. The difference of overall survival between the two groups was estimated using Kaplan-Meier curve and tested for significance using log-rank test by SPSS 17.0 software (SPSS, Inc., Chicago, IL, USA). GraphPad Prism 5 (GraphPad Software, USA) was used to perform statistical analysis for the results of RT-qPCR, CCK-8, wound healing and Transwell assays. Significance between groups was evaluated by one way analysis of variance followed by a Bonferroni post hoc test. $\mathrm{P}<0.05$ was considered statistically significant.

\section{Results}

TRPM2 is significantly correlated with patient survival. Following the data analysis of genes using the Kaplan-Meier curve and the log-rank test, TRPM2 was selected as a potential candidate marker of prognosis. The survival analysis revealed that in 159 patients, the mutation status of TRPM2 was significantly correlated with patient survival $\left(\mathrm{P}=1.0416 \times 10^{-2}\right.$; Table I). The somatic mutations of TRPM2 in this cohort are detailed in Table II. Furthermore, the enhanced expression level affected survival among 91 patients $\left(\mathrm{P}=4.2253 \times 10^{-2}\right.$; Fig. 1). Gene expression correlation analysis revealed that TRPM2 was strongly correlated with the expression of probable phospholipid-transporting ATPase IM (ATP8B4), $\gamma$-parvin (PARVG), tudor domain containing 9 (TDRD9), Toll-like receptor (TLR7) and Scm-like with four MBT domains protein 2 (SFMBT2) (Table III).

TRPM2 is successfully overexpressed in the overexpression group and suppressed in the siRNA group. RT-qPCR analysis demonstrated that compared with the empty vector group, TRPM2 was successfully overexpressed in the Hilymax-TRPM2 OverExp group ( $\mathrm{P}<0.05$; Fig. 2). In addition, the expression level of TRPM2 was successfully knocked down in the Hilymax-TRPM2 siRNA group compared with the scramble siRNA group ( $\mathrm{P}<0.05$; Fig. 2$)$.
Overexpression of TRPM2 enhances the proliferation of PANC-1 cells. The results of the CCK- 8 assay demonstrated that TRPM2 successfully enhanced PANC-1 cell proliferation in the Hilymax-Trpm2 OverExp group compared with the empty vector group ( $\mathrm{P}<0.05$; Fig. 3 ) at the 48 -h time interval, whereas the Hilymax-Trpm2 siRNA group exhibited an inhibitory effect compared with the scramble siRNA group $(\mathrm{P}<0.05$; Fig. 3). There were no significant differences between the vector group and the empty vector group at the $24 \mathrm{~h}$ time interval, however there was a significant difference between the TRPM2 siRNA group compared with the scramble siRNA group (Fig. 3).

Overexpression of TRPM2 enhances the migratory ability of PANC-1 cells. The results of the scratch wound-healing assay revealed that the migratory ability of PANC-1 cells was significantly enhanced following overexpression of TRPM2 $(\mathrm{P}<0.01$; Fig. 4), however, this was significantly suppressed in the RNA interfering group ( $\mathrm{P}<0.001 ;$ Fig. 4).

Overexpression of TRPM2 enhances the invasive ability of PANC-1 cells. Invasive ability was determined via Transwell assays using Matrigel, and the results demonstrated a significantly enhanced invasive ability in the OverExp group compared with the empty vector group $(\mathrm{P}<0.01$; Fig. 5). The siRNA group exhibited fewer invaded cells in the lower chamber of the microwell ( $\mathrm{P}<0.01$; Fig. 5).

\section{Discussion}

The TRPM2 gene encodes a tetrameric cation channel that is permeable to sodium, calcium and potassium, and is activated by free intracellular adenosine 5'-diphosphate (ADP)-ribose $(15,16)$. The encoded protein, also activated by oxidative stress, may induce susceptibility to cell death $(17,18)$. According to previous studies, TRPM2 may induce apoptosis in different types of cancer (19,20). However, Huang et al (21) reported opposite effects of TRPM2 in pancreatic cancers.

According to the data analysis performed in the present study, it was revealed that the mutated TRPM2 gene exhibits a marked negative correlation with patient survival rate compared with the normal control group. The higher TRPM2 is expressed in cancerous tissue, the shorter the survival time exhibited by PDAC patients. The results of the in vitro analyses in the present study revealed that the overexpression of TRPM2 enhanced cell proliferation and invasive ability, and these findings are consistent with the results of the data analysis. Therefore, it may be suggested that TRPM2 expression levels are markedly associated with proliferation, invasive ability and poor prognosis in patients with PDAC. Thus, TRPM2 represents a potential therapeutic target and prognostic marker for the treatment of patients with PDAC.

The results of the gene expression correlation analysis demonstrated that TRPM2 is strongly correlated with the expression levels of ATP8B4, PARVG, TDRD9, TLR7 and SFMBT2. Among these genes, TLR7 has previously been suggested to be associated with the progression of pancreatic cancer (22-25). TLRs are expressed in pancreatic cancer cell lines and numerous human cancer cell lines; however, 


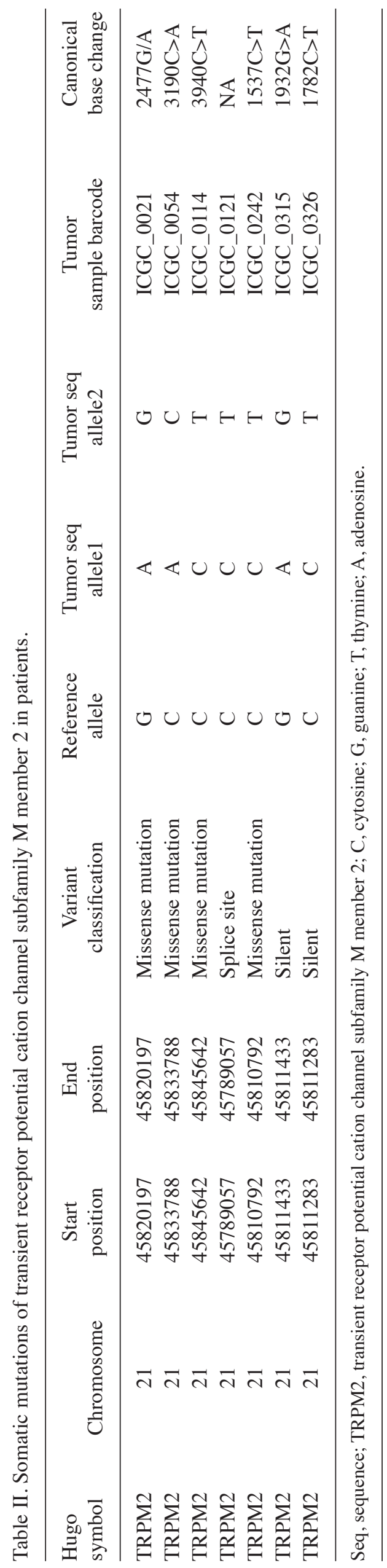

Table III. Gene expression correlation analysis with transient receptor potential cation channel subfamily M member 2 .

\begin{tabular}{llc}
\hline Ensembl & Gene & Correlation coefficient \\
\hline ENSG00000104043 & ATP8B4 & 0.574108 \\
ENSG00000156414 & TDRD9 & 0.526303 \\
ENSG00000198879 & SFMBT2 & 0.520375 \\
ENSG00000138964 & PARVG & 0.511799 \\
ENSG00000196664 & TLR7 & 0.503315
\end{tabular}

ATP8B4, probable phospholipid-transporting ATPase IM; TDRD9, tudor domain containing 9; SFMBT2, Scm-like with four MBT domains protein 2; PARVG, $\gamma$-parvin; TLR7, Toll-like receptor 7.

TLRs are not expressed in the healthy pancreas (26). The expression levels of phosphorylated-extracellular signal-regulated kinase (12) $1 / 2$ are upregulated following TLR7 activation (20), suggesting that the activation of TLR7 is at least partially associated with the mitogen-activated protein kinase-ERK1/2 pathway in BxPC-3 pancreatic cancer cells (22). Furthermore, Grimmig et al (23) revealed that chronic inflammation-mediated TLR7/TLR8 signaling may result in pancreatic cancer cell growth and chemoresistance.

The ATP8B4 gene can encode a P4-ATPase flippase complex, a member of the cation transport ATPase (P-type) family and type IV subfamily (27). Ni et al (27) suggested that ATP8B4 may be a potential prognostic marker and a therapeutic target in the treatment of patients with multiple myeloma who are B-Cell chronic lymphocytic lymphoma/small lymphocytic Lymphoma (BCL)-1/JHt(11;14) (q13;q32) translocation positive.

PARVG, a member of the parvin protein family, is an actin-binding protein associated with focal adhesion (28). Chen et al (29) revealed that four DNA methylation signatures (phospholipase C $\beta 2$, Rac family small GTPase 2, vav guanine nucleotide exchange factor 1 and PARVG) are strongly associated with the prognosis of renal clear cell carcinoma.

TDRD9, a protein coding gene, is associated with pathways including mitotic prophase and PIWI-interacting RNA biogenesis (30-32). At present, there is no evidence to suggest that TDRD9 has an association with cancer.

Mammalian SFMBTs have been suggested to be polycomb group repressors (33). Lee et al (33) demonstrated that transcriptional repression was associated with human SFMBT2, which binds preferentially to methylated histone $\mathrm{H} 3$ and $\mathrm{H} 4$. In addition, it has been revealed that SFMBT2 regulates cell proliferation via epigenetic regulation of homeobox B13 gene expression in the DU145 prostate cancer cell line (34).

Further research is required to investigate the association between TRPM2 and these five genes in the mechanism of promoting pancreatic cancer.

In addition, $\mathrm{Li}$ et al (35) demonstrated that $\mathrm{H}_{2} \mathrm{O}_{2}$-mediated activation of the TRPM2 pathway enhanced the migratory ability of HeLa and prostate cancer cells by inducing filopodia formation, inducing the degradation of actin fibers and inducing the decomposition of focal adhesions. Bauer et al (36) reported 
Table IV. Primer and siRNA information.

Primer

Homo-TRPM2-F

Homo-TRPM2-R

Homo-GAPDH-F

Homo-GAPDH-R

TRPM2-siRNA sense

TRPM2-siRNA antisense

Scramble siRNA sense

Scramble siRNA antisense
Sequence $\left(5^{\prime}-3^{\prime}\right)$

Amplicon length, base pairs
158

158

149

149

N/A

$\mathrm{N} / \mathrm{A}$

N/A

$\mathrm{N} / \mathrm{A}$

F, forward; R, reverse; TRPM2, Transient receptor potential cation channel subfamily M member 2; si, small interfering.

A

A

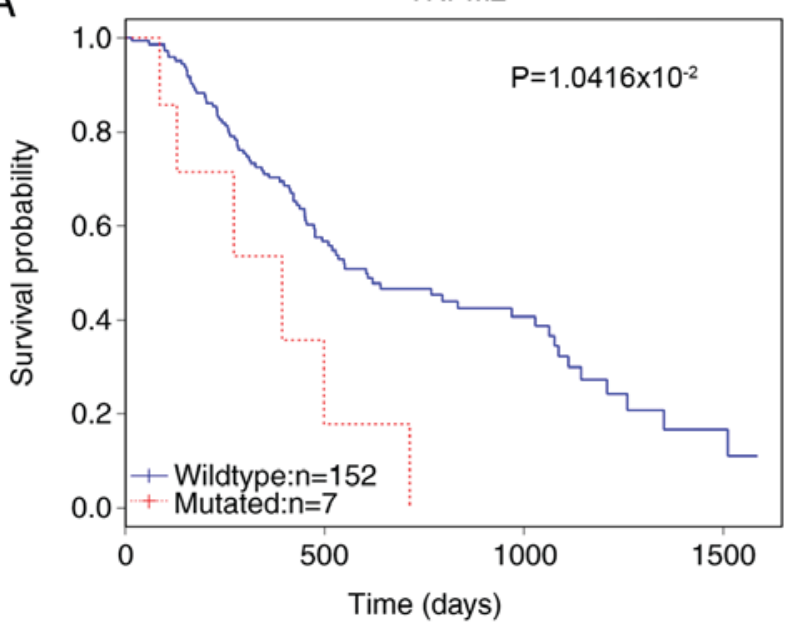

B

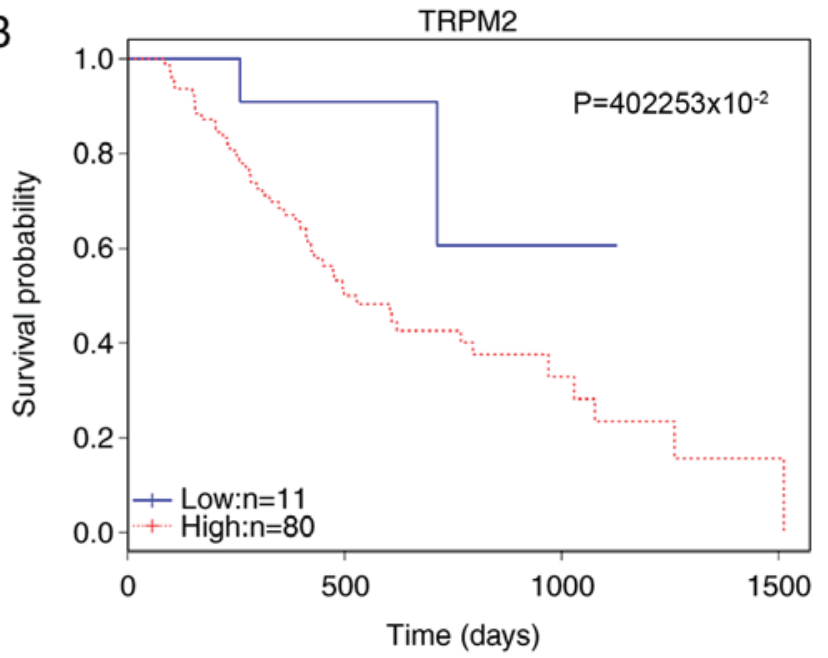

Figure 1. Survival analysis of TRPM2 mutations and gene expression. The overall survival rates of patients are presented according to (A) gene mutation status and (B) expression level. Wildtype indicates a group of patients without gene mutation. TRPM2, transient receptor potential cation channel subfamily $\mathrm{M}$ member 2.

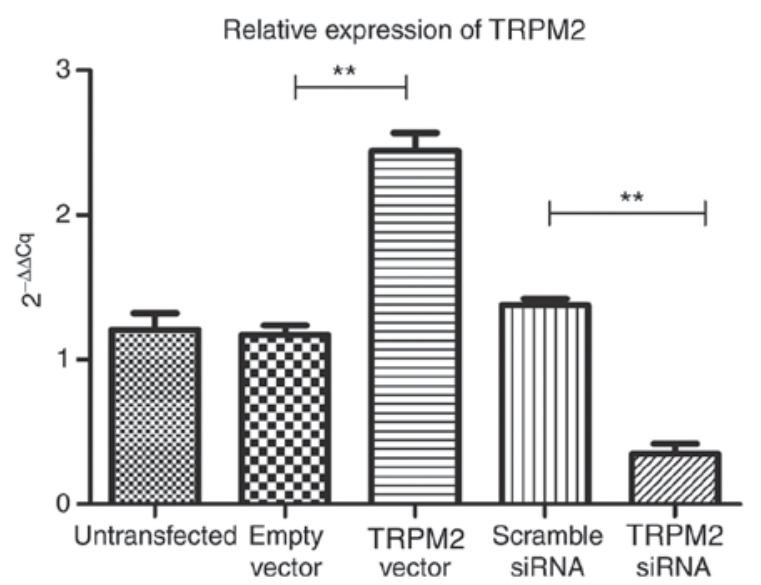

Figure 2. Reverse transcription-quantitative polymerase chain reaction analysis results in the different experimental groups. ${ }^{* *} \mathrm{P}<0.01$ vs. TRPM2 vector or Scramble siRNA vs. TRPM2 siRNA. TRPM2, transient receptor potential cation channel subfamily $\mathrm{M}$ member 2 ; si, small interfering.

that the expression of ADP-ribose, a calcium channel activator, was increased by NAD-dependent protein deacetylase sirtuin- 6

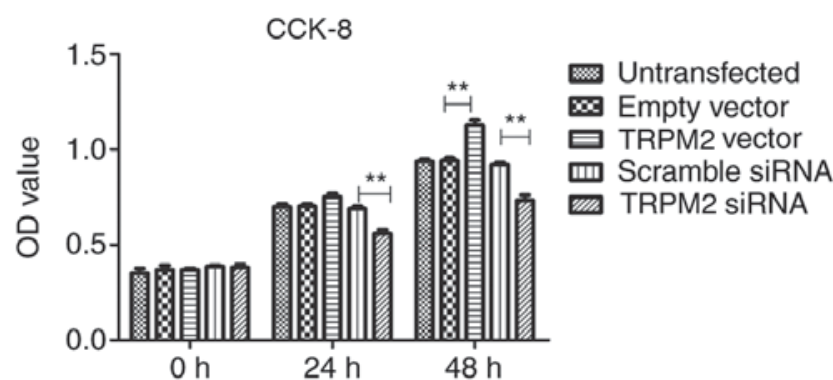

Figure 3. CCK-8 array results in the untransfected, empty vector, TRPM2 vector, scramble siRNA and TRPM2 siRNA groups at $0-, 24-$, and 48-h time intervals. ${ }^{* *} \mathrm{P}<0.01$. TRPM2, transient receptor potential cation channel subfamily M member 2; si, small interfering; CCK-8, Cell Counting Kit-8; OD, optical density.

(SIRT6), which in turn enhanced the expression of interleukin 8 and tumor necrosis factor pro-inflammatory cytokines and promoted pancreatic cancer cell migration. Thus, TRPM2 may promote PDAC metastasis via the aforementioned mechanisms, however, further investigation is required to determine the underlying molecular mechanisms. 

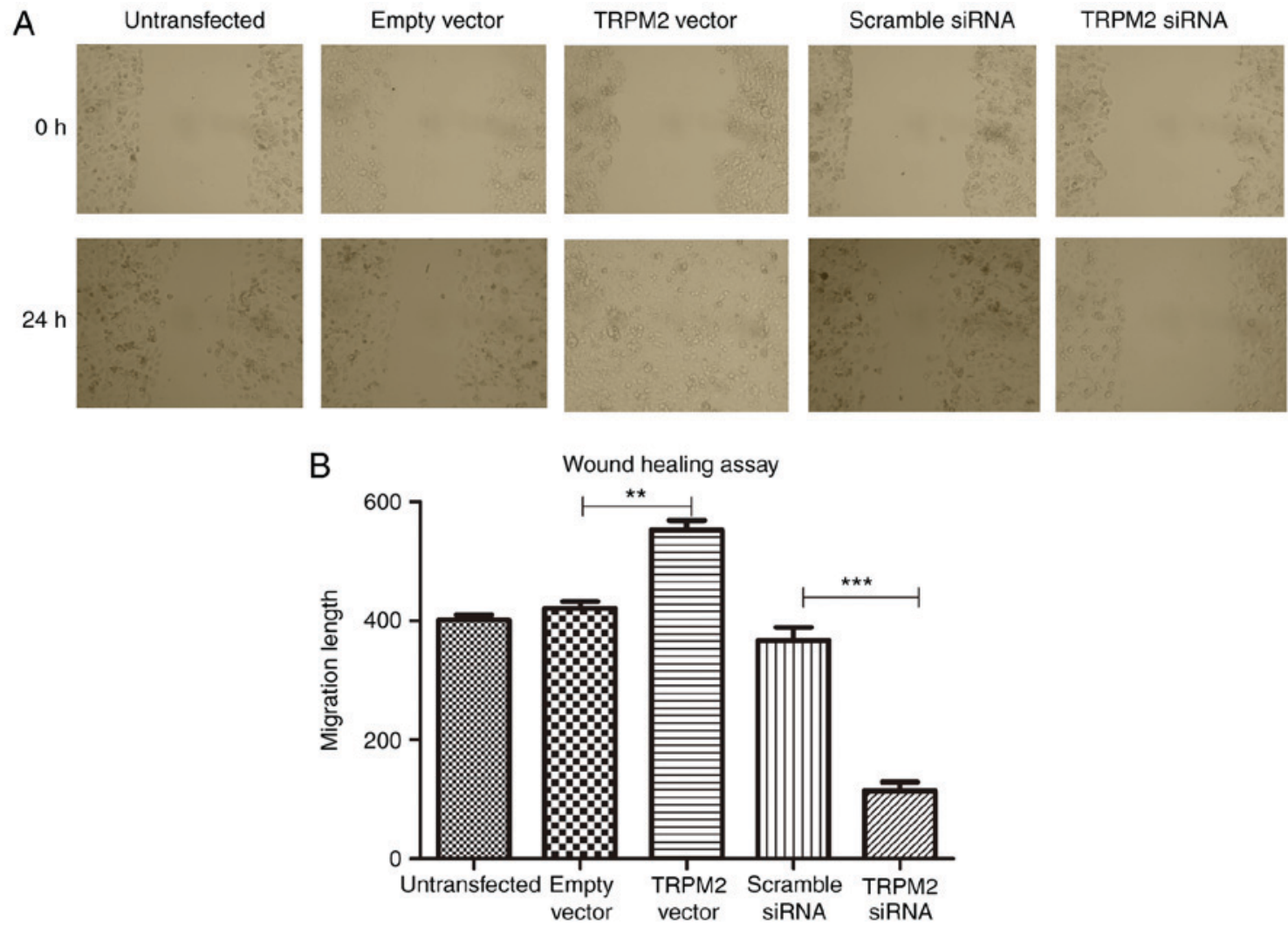

Figure 4. Scratch wound-healing assay results. (A) Images of all groups at 0 - and 24-h time intervals post-injury (magnification, x100). (B) Quantitative analysis of scratch wound-healing assay results among untransfected, empty vector, TRPM2 vector, scramble siRNA and TRPM 2 siRNA groups at $24 \mathrm{~h}$ post-injury. ${ }^{* *} \mathrm{P}<0.01,{ }^{* * *} \mathrm{P}<0.001$. TRPM2, transient receptor potential cation channel subfamily M member 2 ; si, small interfering.
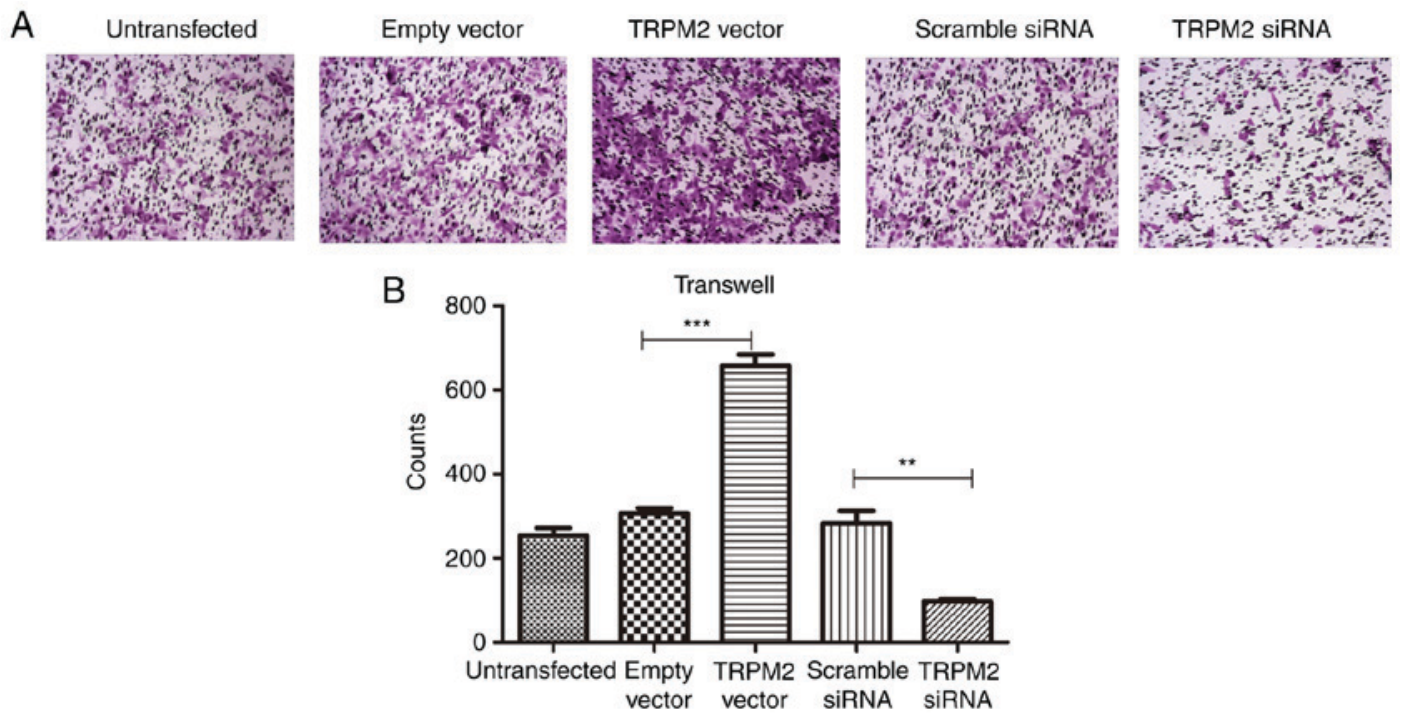

Figure 5. Transwell assay results suggest that the TRPM2 overexpression group has a stronger invasive ability and TRPM2 siRNA group has a weaker invasive ability. (A) Images under microscopy (magnification, x100). (B) Quantitative analysis of Transwell assay results among untransfected, empty vector, TRPM2 vector, scramble siRNA and TRPM2 siRNA groups. ${ }^{* *} \mathrm{P}<0.01,{ }^{* * * *} \mathrm{P}<0.001$. TRPM2, transient receptor potential cation channel subfamily M member 2 ; si, small interfering.

The results of the survival analyses regarding TRPM2 mutations suggest a poor prognosis for the TRPM2 mutation group compared with in the wild type group. The results of the present study have demonstrated that overexpression of TRPM2 promotes PANC-1 cell growth, migration and invasion ability. Furthermore, the results of the present study hypothesize that TRPM2 may mediate cell proliferation via regulation of TLR7 and SFMBT2. In addition, TRPM2 may be associated with the promotion of invasion and migration via the regulation of PARVG and SIRT6, or by inducing filopodia formation, however, the mechanism underlying this process remains to be determined. 


\section{Acknowledgements}

We would like to thank Professor Wei Zuo for generously providing us with lab space and facilities, Dr. Yu Ma, Timing Zhen and Sibo Zhu for technical assistance, and for assisting with manuscript preparation.

\section{Funding}

The present study was supported by Core Department Supporting Funding from Tongji Hospital, Tongji University (Tonji, China).

\section{Availability of data and materials}

The datasets used and analyzed during the current study are available from the corresponding author on reasonable request.

\section{Authors' contributions}

BMS designed the research. RL and YFW conducted the research. QNC and ZYL helped collect and interpret the data. SX and BYW helped culturing cells, collecting reference articles and writing the manuscript. All authors read and approved the final manuscript.

\section{Ethics approval and consent to participate}

Not applicable.

\section{Consent for publication}

Not applicable.

\section{Competing interests}

The authors declare that they have no competing interests.

\section{References}

1. Lin QJ, Yang F, Jin C and Fu DL: Current status and progress of pancreatic cancer in China. World J Gastroenterol 21: 7988-8003, 2015.

2. Warshaw AL and Fernández-del Castillo C: Pancreatic carcinoma. N Engl J Med 326: 455-465, 1992.

3. Li D, Xie K, Wolff R and Abbruzzese JL: Pancreatic cancer. Lancet 363: 1049-1057, 2004.

4. Hruban RH, Maitra A and Goggins M: Update on pancreatic intraepithelial neoplasia. Int J Clin Exp Pathol 1: 306-316, 2008.

5. Feldmann G, Beaty R, Hruban RH and Maitra A: Molecular genetics of pancreatic intraepithelial neoplasia. J Hepatobiliary Pancreat Surg 14: 224-232, 2007.

6. Korc M: Pancreatic cancer-associated stroma production. Am J Surg 194 (4 Suppl): S84-S86, 2007.

7. Miyamoto H, Murakami T, Tsuchida K, Sugino H, Miyake $H$ and Tashiro S: Tumor-stroma interaction of human pancreatic cancer: Acquired resistance to anticancer drugs and proliferation regulation is dependent on extracellular matrix proteins. Pancreas 28 38-44, 2004.

8. De Wever O and Mareel M: Role of tissue stroma in cancer cell invasion. J Pathol 200: 429-447, 2003.

9. Ding K, Lopez-Burks M, Sanchez-Duran JA, Korc M and Lander AD: Growth factor-induced shedding of syndecan-1 confers glypican-1 dependence on mitogenic responses of cancer cells. J Cell Biol 171: 729-738, 2005.
10. Kleeff J, Ishiwata T, Kumbasar A, Friess H, Büchler MW, Lander AD and Korc M: The cell-surface heparan sulfate proteoglycan glypican-1 regulates growth factor action in pancreatic carcinoma cells and is overexpressed in human pancreatic cancer. J Clin Invest 102: 1662-1673, 1998.

11. Bailey P, Chang DK, Nones K, Johns AL, Patch AM, Gingras MC, Miller DK, Christ AN, Bruxner TJ, Quinn MC, et al: Genomic analyses identify molecular subtypes of pancreatic cancer. Nature 531: 47-52, 2016

12. Waddell N, Pajic M, Patch AM, Chang DK, Kassahn KS, Bailey P, Johns AL, Miller D, Nones K, Quek K, et al: Whole genomes redefine the mutational landscape of pancreatic cancer. Nature 518: 495-501, 2015.

13. Edgar R, Domrachev M and Lash AE: Gene Expression Omnibus: NCBI gene expression and hybridization array data repository. Nucleic Acids Res 30: 207-210, 2002.

14. Livak KJ and Schmittgen TD: Analysis of relative gene expression data using real-time quantitative PCR and the 2(-Delta Delta C(T)) method. Methods 25: 402-408, 2001.

15. Ishii M, Shimizu S, Hagiwara T, Wajima T, Miyazaki A, Mori Y and Kiuchi Y: Extracellular-added ADP-ribose increases intracellular free $\mathrm{Ca} 2+$ concentration through $\mathrm{Ca} 2+$ release from stores, but not through TRPM2-mediated $\mathrm{Ca} 2+$ entry, in rat beta-cell line RIN-5F. J Pharmacol Sci 101: 174-178, 2006.

16. Inamura K, Sano Y, Mochizuki S, Yokoi H, Miyake A, Nozawa K, Kitada C, Matsushime H and Furuichi K: Response to ADP-ribose by activation of TRPM2 in the CRI-G1 insulinoma cell line. J Membr Biol 191: 201-207, 2003.

17. Zhang W, Chu X, Tong Q, Cheung JY, Conrad K, Masker K and Miller BA: A novel TRPM2 isoform inhibits calcium influx and susceptibility to cell death. J Biol Chem 278: 16222-16229, 2003.

18. Ishii M, Hagiwara T, Mori Y and Shimizu S: Involvement of TRPM2 and L-type $\mathrm{Ca}^{2} *$ channels in $\mathrm{Ca}^{2} *$ entry and cell death induced by hydrogen peroxide in rat $\beta$-cell line RIN-5F. J Toxicol Sci 39: 199-209, 2014.

19. Tao KY, Li XX, Xu WZ, Wang Y, Zhu SM, Xie HX, Luo WH, $\mathrm{Xu}$ YJ and Xu XL: Prognostic role of apoptosis-related gene functional variants in advanced non-small-cell lung cancer patients treated with first-line platinum-based chemotherapy. Onco Targets Ther 8: 147-155, 2015.

20. Orfanelli U, Jachetti E, Chiacchiera F, Grioni M, Brambilla P, Briganti A, Freschi M, Martinelli-Boneschi F, Doglioni C, Montorsi F, et al: Antisense transcription at the TRPM2 locus as a novel prognostic marker and therapeutic target in prostate cancer. Oncogene 34: 2094-2102, 2015.

21. Huang C, Qin Y, Liu H, Liang N, Chen Y, Ma D, Han Z, Xu X, Zhou X, He J and Li S: Downregulation of a novel long noncoding RNA TRPM2-AS promotes apoptosis in non-small cell lung cancer. Tumour Biol 39: 1010428317691191, 2017.

22. Wang F, Jin R, Zou BB, Li L, Cheng FW, Luo X, Geng X and Zhang SQ: Activation of Toll-like receptor 7 regulates the expression of IFN- $\lambda 1$, p53, PTEN, VEGF, TIMP-1 and MMP-9 in pancreatic cancer cells. Mol Med Rep 13: 1807-1812, 2016.

23. Grimmig T, Matthes N, Hoeland K, Tripathi S, Chandraker A, Grimm M, Moench R, Moll EM, Friess H, Tsaur I, et al: TLR7 and TLR8 expression increases tumor cell proliferation and promotes chemoresistance in human pancreatic cancer. Int J Oncol 47: 857-866, 2015.

24. Eigenbrod T and Dalpke AH: TLR7 inhibition: A novel strategy for pancreatic cancer treatment? JAKSTAT 2: e23011, 2013.

25. Ochi A, Graffeo CS, Zambirinis CP, Rehman A, Hackman M, Fallon N, Barilla RM, Henning JR, Jamal M, Rao R, et al: Toll-like receptor 7 regulates pancreatic carcinogenesis in mice and humans. J Clin Invest 122: 4118-4129, 2012.

26. Vaz J and Andersson R: Intervention on toll-like receptors in pancreatic cancer. World J Gastroenterol 20: 5808-5817, 2014.

27. Ni IB, Ching NC, Meng CK and Zakaria Z: Translocation $t(11 ; 14)$ (q13;q32) and genomic imbalances in multi-ethnic multiple myeloma patients: A Malaysian study. Hematol Rep 4: e19, 2012.

28. Danger R, Thervet E, Grisoni ML, Puig PL, Pallier A, Tregouet D, Lecorre D, Giral M, Legendre C, Soulillou JP and Brouard S: PARVG gene polymorphism and operational renal allograft tolerance. Transplant Proc 44: 2845-2848, 2012.

29. Chen G, Wang Y, Wang L and Xu W: Identifying prognostic biomarkers based on aberrant DNA methylation in kidney renal clear cell carcinoma. Oncotarget 8: 5268-5280, 2017.

30. Zhou J, Leu NA, Eckardt S, McLaughlin KJ and Wang PJ: STK31/TDRD8, a germ cell-specific factor, is dispensable for reproduction in mice. PLoS One 9: e89471, 2014. 
31. Kotov AA, Akulenko NV, Kibanov MV and Olenina LV: Dead-box RNA helicases in animal gametogenesis. Mol Biol (Mosk) 48: 22-35, 2014 (In Russian).

32. Lim AK, Lorthongpanich C, Chew TG, Tan CW, Shue YT, Balu S, Gounko N, Kuramochi-Miyagawa S, Matzuk MM, Chuma S, et al: The nuage mediates retrotransposon silencing in mouse primordial ovarian follicles. Development 140: 3819-3825, 2013.

33. Lee K, Na W, Maeng JH, Wu H and Ju BG: Regulation of DU145 prostate cancer cell growth by Scm-like with four mbt domains 2. J Biosci 38: 105-112, 2013.

34. Gwak J, Shin JY, Lee K, Hong SK, Oh S, Goh SH, Kim WS and Ju BG: SFMBT2 (Scm-like with four mbt domains 2) negatively regulates cell migration and invasion in prostate cancer cells. Oncotarget 7: 48250-48264, 2016.

35. Li F, Abuarab N and Sivaprasadarao A: Reciprocal regulation of actin cytoskeleton remodelling and cell migration by $\mathrm{Ca} 2+$ and Zn2+: Role of TRPM2 channels. J Cell Sci 129: 2016-2029, 2016.
36. Bauer I, Grozio A, Lasigliè D, Basile G, Sturla L, Magnone M, Sociali G, Soncini D, Caffa I, Poggi A, et al: The NAD+-dependent histone deacetylase SIRT6 promotes cytokine production and migration in pancreatic cancer cells by regulating $\mathrm{Ca} 2+$ responses. J Biol Chem 287: 40924-40937, 2012.

This work is licensed under a Creative Commons Attribution-NonCommercial-NoDerivatives 4.0 International (CC BY-NC-ND 4.0) License. 